\title{
Health Lifestyles and Their Influence on Chinese Oldest- old's Health Outcomes -Evidence From a Latent Class Analysis
}

\section{Li Zhang}

China University of Political Science and Law https://orcid.org/0000-0001-5843-6550

\section{Xiangyang Bi}

Minzu University of China

Zhihong Ding ( $\sim$ dingzhihong123@sohu.com )

Central University of Finance and Economics

\section{Research article}

Keywords: health lifestyles, socioeconomic status, latent class analysis, Chinese older adults, CLHLS

Posted Date: September 21st, 2020

DOI: https://doi.org/10.21203/rs.3.rs-62228/v1

License: (c) (i) This work is licensed under a Creative Commons Attribution 4.0 International License. Read Full License 


\section{Abstract}

Background

A strong association between individual health behaviors and health outcomes has been emphasized by previous analyses. However, how individual health behaviors can be classified into health lifestyles and the manner in which health lifestyles have impacted Chinese oldest-old's health status are largely unknown.

Methods

Analyzing the 2014 Chinese Longitudinal Healthy Longevity Survey (CLHLS), latent class analysis was applied to identify predominant health lifestyles among Chinese oldest-old aged 85 to 105.

Results

Four distinct classes representing health lifestyles emerged. Health lifestyles were found to be strongly associated with Chinese oldest-old's health outcomes which were measured by self-rated health, functional independence, cognitive function and chronic diseases, even after controlling for demographic features as well as individual and parental socioeconomic disadvantage. Findings also showed a convergence of health disparities caused by demographic and SES characteristics in very old age.

Conclusions

Chinese oldest-old showed four predominant health lifestyles with only $21.9 \%$ of the sample had consistently healthy lifestyle behaviors. The significant influence of health lifestyles on health remained after age 85 , .highlighting the importance of promoting health lifestyles to advance the oldest-old's health status.

\section{Background}

In recent years, researchers have begun to use clustered health lifestyles to explain the health disparities among individuals [1-4]. The benefit of this perspective is that it has extended the scopes of existing analyses on individual health behaviors to classified health lifestyles. Individual or single health behaviors that have been commonly used in prior analyses included poor dietary habits, cigarette smoking, excessive alcohol consumption et al. [5-9]. Scholars who promoted the health lifestyle approach argued that health behaviors tend to cluster in ways that reflect the social and structural contexts of individuals, which in turn affects individual health status [10]. This is because behaviors are not isolative, but co-occur with another [4]. Health lifestyle theories therefore contended that concentrating on single behaviors or small subsets of risky behaviors provides limited insight into health behavior patterns [11]. Thus, considering multiple behaviors simultaneously is a more appropriate strategy that creates larger and more enduring behavior change to improve individual health [12].

As far as studies on health status of Chinese elders, abundant analyses have documented a strong link between health behaviors and health outcomes among Chinese older adults [13-16]. Nevertheless, as studies focusing on other social contexts, most research on Chinese oldest-old also focused on single health behaviors. Since the sub-population of oldest-old is growing at extraordinary speed in China, it is important to explore potential factors that may improve the oldest-old's health status to alleviate the burden of the society as well as the family caregivers. Under such a proceeding, this research intended to take the health lifestyle approach, i.e., a combination of multiple health-related behaviors, to attain a better understanding of health-related practices and their relationship with Chinese oldest-old's health outcomes. Relying on latent class analysis strategy, the study used 2014 wave of the Chinese Longitudinal 
Health and Longevity Survey (CLHLS 2011), a nationally presentative data, to include health behaviors from multiple domains to present a relatively more comprehensive picture of health behaviors among Chinese oldest-old. It also aimed to elucidate how health lifestyles have shaped Chinese oldest-old's health outcomes. Findings based on analyzing nationally representative data in China are valuable to address disease prevention and health promotion related issues among the oldest-old in world countries. Exploring how clustered health behaviors influence the oldestold's health outcomes can also expand theories explaining health disparities among elders in general.

\section{The health lifestyle approach and prior literature}

The health lifestyle approach can be considered as a theoretical development in research of health disparities. The concept of health lifestyle was derived from Weber's idea of lifestyles as the interaction of life choices and life chances. Weber reasoned that lifestyles are not associated with individuals but groups of people with similar social status and backgrounds. Such a definition has been further expanded to include factors such as understandings of what good health means, health norms, policy environments et al. (Krueger et al., 2009). Bourdieu [17] further treated health lifestyles as broad and potentially unobservable orientations that organize patterns of behaviors. Health lifestyle perspectives emphasized more on patterns of behaviors rather than single behaviors. The perspectives highlighted social, cultural and economic forces on individual choices of health behaviors [10].

Some pioneer studies using the health lifestyle approach have been conducted to examine the general population. These studies can be classified as the following groups: First, linking personal characteristics, such as gender and age, to individual health lifestyles $[10,18]$. Second, demonstrating a strong positive association between SES and clustered health behaviors among adults in different social contexts [19-22]. Third, exploring determinants of health lifestyle behaviors in adolescence and revealing how early age health lifestyle behaviors had imprints on one's health behaviors in adulthood $[23,24]$. Fourth, documenting significant influence of health lifestyles on individual health outcomes, including mental health, self-rated health $(\mathrm{SRH})$ and alike $[2,25,26]$ and underlining the positive effects of health lifestyle behaviors on diseases prevention $[27,28]$.

Health lifestyle approach has also been found useful in epidemiological studies examining health and mortality among older adults in a variety of countries. By operationalizing healthy lifestyle behaviors as physical activities, consumption of fruits and vegetables, and whether smoking, Martin-Maria and colleagues' [29] study showed significantly positive effect of healthy lifestyle behaviors on subjective well-being among Spain sample aged 65 and over. Through studying multiple lifestyle behaviors of older persons in Korea and Amsterdam, scholars highlighted that participation in healthy lifestyles contributed to the maintenance of functional independence (measured as ADL and IADL) and cognitive function in later life $[30,31]$. The study based on examining lifestyle behaviors including non-smoking and physical activity among elders in Sweden revealed that a low risk health behavior profile could add five years to women's lives and six years to men's after age 75 [32].

The above reviewed analyses have provided guidance to this current research investigating the link between health lifestyles to Chinese oldest-old's health outcomes. The selection of health lifestyles as well as health status measures was based on the commonly used measures in previous studies. The analysis answered two main questions: First, what are predominant health lifestyles of the Chinese oldest-old? Second, how have these main health lifestyles shaped Chinese oldest-old's health outcomes? Findings of this study were expected to fill the voids of prior literature by investigating Chinese oldest-old's health disparities from single health behaviors. Results based on analyzing the China data were also supposed to enrich health lifestyle theories on the whole. Below the paper moved to an introduction of data, measures and methods used in the study.

\section{Data, measures and methods}


Data came from the 2014 Chinese Longitudinal Healthy Longevity Survey (CLHLS) which was conducted in randomly selected half of the counties/cities in 22 provinces of China. Until now, 7 waves $(1998,2000,2002,2005,2008,2011$ 12 , and 2014) of survey data have been collected. The survey was initially launched to meet the needs for scientific research on the oldest-old. Thus, the dataset provided an excellent source for studying the oldest-old in China. Previous literature showed that persons who reported age 106 or higher were considered as invalid cases [33]. Therefore, persons aged 106 and higher were excluded from this study due to insufficient information to validate their reported extremely high age. The study eventually obtained 3,416 oldest-old aged 85 to 105, with 2,025 males and 1,391 females.

\section{Measures}

\section{Health lifestyle indicators}

Health lifestyles measures used in previous analyses can be classified as the following categories: (1) dietary patterns (including eating fruits, vegetables, breakfast et al.), (2) smoking, alcohol consumption, (3) sleep, (4) obesity and physical activity, (5) seat belt wearing and media use, (6) body mass index (BMI), and (7) regular physical examination [34-41]. The selection of health lifestyle indicators in this research has been largely guided by prior studies and four key domains were applied, including dietary behaviors, smoking and alcohol use, sleep, and physical and leisure activities.

The first domain was dietary behaviors. In the CLHLS survey, the respondent was asked the frequency of eating or drinking fresh fruit, fresh vegetables and tea. The study coded these three variables as dichotomous ones with labeling respondents answering "almost everyday" and as " 1 " and " 0 " if otherwise. Tea consumption was considered because previous research pointed out that tea drinking related to longevity and reduced risk of mortality and death from cardiovascular diseases [42]. Tea consumption was thus used as an important health lifestyle behavior in this study.

The second domain related to smoking and alcohol use. Since the variables measuring the respondent's exact amount of cigarette or alcohol consumption had an extremely large amount of missing values with responding rates lower than $20.0 \%$ of the total sample, the research applied other measures. Those measures relied on CLHLS survey questions asking the respondent whether he or she smoked or drank alcohol "in the past" and "at present". The respondent who never smoked in the past or at present was coded as " 0 " and " 1 " if otherwise. It was assumed that for those individuals who smoked in the past and was still smoking when the survey was conducted was a heavy smoker; the same rationale and coding strategy were also applied to the alcohol consumption variable.

Sleep was the third domain which was represented by two indicators: sleeping duration and sleep quality. The study dichotomized the sleep duration variable as " 1 " indicating having 8 hours or more sleep each day and " 0 " as having less than 8 hours sleep. The sleep quality variable was dichotomized with those who reported their sleep quality as "good" and "very good" as " 1 " and poor sleep quality as " 0 " (including the categories that were originally coded in the survey as 'so so', 'bad' and 'very bad').

The fourth domain was physical and leisure activities. The research relied on two survey questions asking whether the respondent exercised regularly in the past and at present to determine if he or she was physically active. Those who exercised regularly both at present and during the past were coded as "1", and "0" if otherwise. The research also classified leisure activities into sedentary actives and active activities. Sedentary activities were such as reading newspapers/books, playing cards and /or mah-jong, and watching TV and/or listening to radio. Active activities included raising domestic animals, doing gardening work et al. For those who participated in leisure activities almost everyday were coded as " 1 " and " 0 " if otherwise. 
The health outcome measures used in this research were consistent with measures used in previous research, including self-rated health (SRH) [43,44], cognitive function [45-47], chronic diseases [13,48] and activity of daily living (ADL) $[49,50]$. The respondent's $S R H$ was coded as a continuous variable ( $1=$ very bad, $5=$ very good). Chronic disease variable was measured by whether the respondent reported any chronic diseases ( $1=y e s, 0=$ no). The CLHLS survey asked the respondent whether he or she was suffering from 24 types of chronic diseases, including: hypertension, diabetes, heart disease, stroke/ cerebrovascular disease, bronchitis/emphysema/asthma/pneumonia, pulmonary tuberculosis, cataracts, glaucoma, cancer, prostate tumor, gastric or duodenal, Parkinson's disease, bedsore, arthritis, dementia, epilepsy, cholecystitis/cholelith disease, blood disease, rheumatism or rheumatoid disease, chronic nephritis, galactophore disease, uterine tumor, hyperplasia of prostate, and hepatitis. Since the missing values for prostate tumor, chronic nephritis, galactophore disease and hyperplasia of prostate exceeded half of the respondents, these 4 types of chronic diseases were dropped from the analysis. As a result, the study included the rest 20 types of chronic diseases. If the respondent answered he or she was suffering from at least one type of the 20 types of chronic diseases, then the respondent was coded as " 1 " for the chronic disease variable, and " 0 " if otherwise. Cognitive function of the respondent was measured by using the Chinese version of the Mini-Mental State Examination (MMSE). The MMSE was adapted from Folstein, Folstein, and McHugh [51] and tested four aspects of cognitive functioning: orientation, calculation, recall, and language. The total possible score on the MMSE is 30, with lower scores indicating poor cognitive ability. Based on recommendations in the literature, responses of "unable to answer" were coded as incorrect answers [52]. Activity of daily living $(A D L)$ disability was defined as self-reported difficulty with any of the following ADLs items: (a) bathing, (b) dressing, (c) eating, (d) indoor transferring, (e) toileting, and (f) continence. To avoid problems of complications and small sub-sample sizes in model estimation, the ADL functional capacity was dichotomized into "0" (meaning no ADL limitation) and "1" (meaning at least one ADL limitation).

\section{Control variables}

The analysis also controlled for the respondent's demographic characteristics such as age, gender, rural and urban residence. Respondents who lived in cities and towns were classified as urban residents. The respondent's socioeconomic status was also controlled, including years of schooling, per capita household income, and occupation before age 60 . The occupation variable was coded as " 1 " if the respondent held a professional or administrative occupation and "0" if otherwise. Since socioeconomic condition in early childhood has been documented to have a cumulative effect on one's later life health status and mortality $[53,54]$, the early childhood (or parental) SES was controlled as well. These measures included whether the respondent frequently went to bed hungry as a child, education of the respondent's father and the respondent's father's occupation before age 60 (1=professional or administrative job, $0=$ otherwise). Although the percentages of respondents and respondents' fathers who held professional or administrative jobs were low, the occupation measure has been repeatedly used as indicators of one's SES [55-57]. Thus, the validity of the occupation measure representing SES has been proved by previous analyses. Table 1 showed descriptive statistics for all variables.

\section{Methods}

\section{Latent class analysis}

Latent class analysis (LCA) was used to predict membership in latent or unobserved groups. LCA is a statistical method that finds subtypes of related cases (latent classes) from multivariate categorical data. It can be used to find distinct categories considering presence/absence of several symptoms. The rationale of LCA is that given a sample of cases (subjects, objects, respondents, patients, et al.) measured on several variables, one wishes to know if there is a small 
number of basic groups into which cases fall. The results of LCA can be used to classify cases to their most likely latent class. Within each latent class, each variable is statistically independent of every other variable. If one removes the effect of latent class membership on the data, all that remains is randomness. In this study, respondents in a certain latent class shared similar health lifestyle patterns. Each case was assigned a probability of membership in each class.

LCA uses observed data to estimate parameter values for the model. The model parameters are the prevalence of each of $\mathrm{C}$ case subpopulations or latent classes and conditional response probabilities. A randomly selected member of that class will make that response to that item/variable. Parameters are estimated by the maximum likelihood (ML) criterion. The ML estimates are those most likely to account for the observed results. Estimation is usually done with simple iterative numerical methods. The traditional forms of LCA used complicated estimation methods based on matrix manipulation and simultaneous linear equations. Later on, simple iterative proportional fitting was used to find $\mathrm{ML}$ parameter values. In this analysis, since the exact number of health behavior typologies is unknown, an explanatory approach was used. It started with the most parsimonious 1-class model and fitted successive models with increasing numbers of classes. Each latent class solution was replicated 20 times beginning at random starting values. This method included a close examination of item loadings and model fit indices for estimating latent classes [58]. The final number of classes was determined by the conceptual meaning, and commonly used fit measures such as the Akaike Information Criterion (AIC), the Bayesian Information Criterion (BIC) and the value of entropy. The values of these indices for different class categories were shown in Table 2.

When running LCA, the Stata software showed that convergence was not achieved when constructing 5 classes. Considering that the four-class solution provides the most conceptually coherent description of health lifestyles, the four-class solution was chosen as the most appropriate solution that represented health lifestyles among Chinese oldest-old. Since smaller values of AIC and BIC are better and the four-class model had both the smallest AIC and BIC (see Table 2), the statistical data proved that the four-class solution is preferred. As Table 2 presented, the entropy for the four-class model (0.732) was also beyond the criteria for good class separation cutoff point of 0.60 [59]. Thus, the four-class solution was determined to be the best classification type to represent health lifestyles among Chinese oldest-old.

Based on the results of LCA, the paper presented item response probabilities and shares for the analyzed sample for each class in Table 3. Such information clearly showed the four predominant health lifestyles among Chinese oldestold and the percentage distribution of sample among the four classes. Meanwhile, the table also showed the percentage distribution of the respondents for each health behavior, which helped us to describe the patterns of the four classes that represented Chinese oldest-old's health lifestyles.

\section{Descriptive and regression analyses}

The analytical part started with descriptive analysis to report means and percentage distributions of all variables (see Table 1). Multiple regression models were then constructed to predict Chinese oldest-old's health status on the basis of their health lifestyles, controlling for the respondent's demographic and socioeconomic characteristics. Since the health outcome measures of ADL disability and chronic diseases were coded as dichotomous variables, logistic regressions were used to perform the analyses. The other two measures of health status, namely, SRH and cognitive function scores, were continuous variables, ordinary least squared (OLS) regression were therefore applied to show how health lifestyles predict health status of the oldest-old.

\section{Results}


Descriptive statistical results for all variables were presented in Table 1. Among the 3,416 respondents aged 85 to 105 , there was a higher percentage share of rural than urban respondents in the sample $(57.3 \%$ and $42.7 \%$, respectively) and females outnumbered males (59.3\% vs. $40.7 \%)$. The mean age of the sample was 93.1 with a standard deviation of 5.7. As to SES of the respondents, the average reported years of schooling among the oldest-old was 1.5 with a standard deviation of 2.8. And the average schooling year for the respondent's father was 0.5 with a standard deviation of 1.8. The mean household per capita income for the year before the survey was 15,832.8 RMB (which is equivalent to 2,261.8 USD with 1 USD $=7$ RMB), with a standard deviation of 17,233.8. The percentage of the respondents and their fathers who had professional or administrative jobs before retirement was $5.7 \%$ and $2.6 \%$, respectively. About $77.4 \%$ of the studied sample reported being hungry when going to bed in childhood.

The health outcome profile among Chinese oldest-old was fairly good. To illustrate, the average SRH score was 3.3 (between fair and good). About $57.1 \%$ and $34.8 \%$ of the respondents reported having at least one type of chronic diseases and ADL disabilities, respectively. The mean cognitive function score was 22.5 , suggesting a relatively good cognitive function status of Chinese oldest-old.

The health lifestyle patterns can be described as fairly healthy. The studied oldest-old seemed to be frequent fruit and vegetable eaters, with $13.5 \%$ and $49.1 \%$ of them eating fresh fruit and vegetables almost everyday. Tea was also preferred by some oldest-old. Nearly one fifth of them had the habit of drinking tea almost everyday. About $24.9 \%$ and $21.3 \%$ of the studied sample reported themselves as smokers and drinkers, respectively. For three fifth of the sample, sleeping was not an issue since they reported good sleep quality. A slightly over $55.0 \%$ of the sample had 8 or more hours of sleep each day. Considering the very old age of studied sample, the lifestyle of the respondents tended to be more sedentary than active. About $26.8 \%$ of them reporting doing physical exercise before age 60 and were still exercising when surveyed. And $48.4 \%$ and $41.7 \%$ of the oldest-old individuals reported that almost everyday they participated in at least one physical and sedentary type of leisure activity, respectively.

\section{Health lifestyles among Chinese oldest-old}

After choosing the 4-class model as the best fitted latent class model, the study estimated item probabilities for the four identified latent classes. The four predominant Chinese oldest-old's healthy lifestyles (latent classes) and their share of the sample were presented in Table 3. Class 1 can be described as less healthy diet, not smoking, not drinking, poor sleep, low engagement in physical exercise and leisure activities, which contained $32.4 \%$ of the total sample. Sample in this class tended to be nonsmokers or nondrinkers ( $81.9 \%$ and $86.0 \%$, respectively); they had moderate dietary patterns. Sample in this latent class experienced the highest level of inadequate nighttime sleep with those who had 8 hours or more sleep everyday only counted $19.1 \%$ of the total sample. Respondents in this class also showed the lowest probability (12.6\%) of doing physical exercise. Class 2 can be depicted as less healthy diet, not smoking, not drinking, good sleep, lowest engagement in physical exercise and leisure activities. This class consisted of $33.6 \%$ of all respondents, which had the highest percentage share of all sample among the four classes. Similar to class 1 , this class showed moderate dietary pattern and sedentary lifestyles. But the major difference lied in the fact that Class 2 had relatively more smokers and drinkers and this class reported poor sleep. Class 3 , in contrast, can be defined as the "consistent engagement of healthy behaviors" group, which contained about $21.9 \%$ of all respondents. Chinese oldestold in this class reported healthier lifestyles relative to most of their peer across nearly all measures and domains. This

group of the oldest-old reported the highest probabilities of having healthy dietary patterns (eating fresh vegetables and fruits almost everyday; drinking tea almost everyday), not being smokers or drinkers, having enough sleep (>=8 hours per day) and reporting good-quality sleep, participating in active and sedentary leisure activities and doing physical exercises. Class 4 was delineated as moderate diet, smoking and drinking, moderate sleep, moderate exercise and 
leisure activity engagement, which comprised about $12.1 \%$ of all respondents. The most significant feature of this group was smoking and drinking problems. The oldest-old in this latent class reported moderate sleep and diet behaviors as well as activity patterns.

\section{The influence of health lifestyles on Chinese oldest-old's health}

OLS regression models were constructed to predict the respondent's health status that was measured by continuous variables (i.e. cognitive function and self-rated health) and logistic regression analyses were conducted to estimate how health lifestyles predicted the oldest-old's reported ADL disabilities and chronic diseases. Tables 4 and 5 presented OLS and logistic regression results when controlling for the respondent's demographic and socioeconomic factors, respectively. In both Tables 4 and 5, two models were constructed. The first model included the health lifestyle classes as well as the respondent's demographic and SES characteristics; the second model further added the respondent's parental SES variables since prior research showed that parental SES had significant influence on one's later life health status $[49,53]$.

Models 1 and 2 in Table 4 showed that including parental SES variables did not significantly change the statistical results. As compared to class 3 , SRH scores for individuals in class 1 (less healthy diet, not smoking, not drinking, poor sleep, low physical exercise \& leisure activities) were 0.56 lower than the scores of those in class 3 (consistent engagement in healthy behaviors). SRH scores for older adults in class 2 (less healthy diet, not smoking, not drinking, good sleep, lowest physical exercise \& leisure activities) and class 4 (moderate diet, smoking and drinking, moderate sleep, moderate exercise and leisure activity engagement) were 0.21 and 0.19 lower as compared to SRH scores reported by members in class 3 . These results suggested that less healthy lifestyles led to worse self-rated health. Regarding the control variables, males and individuals with higher income tended to reported better SRH.

Regression results of using health lifestyle measures as well as control variables to predict cognitive function status of Chinese oldest-old were showed in Models 3 and 4 in Table 4. Similarly, adding parental SES covariates did not significantly change the statistical results except that the effect of one's education on cognitive function score turned to be nonsignificant. Model 4 showed that as compared to the references group, class 3 , cognitive function scores for the oldest-old in class 1, 2, and 4 decreased by 2.98, 3.45 and 1.37, respectively. The findings again highlighted that less healthy lifestyles linked to worse health outcome that was measured by cognitional function among the oldest-old. As to the covariates, results showed that an increasing age related to lower cognitive function score, whereas being male, having higher education and higher income showed significantly positive effects on cognitive function scores of seniors. Going to bed hungry in childhood had significantly negative effect on the oldestold's cognitive function scores, supporting the cumulative disadvantage theories that childhood disadvantage was still able to explain part of the health disparities in older ages.

When predicting ADL disabilities and chronic disease status, two models were constructed with models 2 and 4 adding parental SES controls. Similar to results showed in Table 4, the results in Table 5 showed that adding parental SES covariates did not significantly change the regression results presented in Models 1 and 3 . The odds of having ADL disabilities among oldest-old in classes 1, 2, 4 were all about 2.8 times of the odds for members in class 3 (see Model 2). The findings indicated that all other 3 lifestyle classes had higher risks of reporting ADL disability as compared to the consistently positive class (class 3 ). Except for class 2 (sedentary group), classes 1 and 4 also showed significantly higher odds of having chronic disease(s) than class 3 . As compared to the respondents in class 3 , sample in class 1 and class 4 were 1.3 and 1.5 times more likely to have chronic disease(s), respectively, when controlling for the covariates. These findings implied that health lifestyles can explain the health disparities among Chinese oldest-old. 
The health differentials among Chinese oldest-old can also be explained by the respondent's demographic and socioeconomic characteristics. An increasing age and having professional or administrative jobs before age 60 increased the risks of elders experiencing ADL disabilities. Whereas being urban decreased the odds of the oldest-old having ADL disabilities. An increasing age lowered the odds of reporting chronic diseases; and higher family income and holding professional or administrative jobs before age 60 increased the likelihood of oldest-old's reporting chronic disease(s). These results seemed to be contradictory to findings of prior research based on the Western society that higher SES led to better health condition. The paper offered possible explanations for such contradiction in the discussion section. In sum, findings of this research proved significant influence of health lifestyles on Chinese oldestold's health status, after controlling for covariates.

\section{Discussion}

With the trend of population aging, the oldest-old has becoming a fast growing group in China. Among the oldest-old, some of them are able to live longer and healthier whereas others suffer long-term disabilities and chronic diseases, which brings a heavy burden to the society as well as their family members. Therefore, a striking array of studies has been conducted discussing the influential factors that have caused health disparities among the oldest-old.

Nevertheless, most of the existing studies examined elderly health from the perspective of considering single behaviors. Thus far, very few studies have applied the health lifestyle approach to investigate health lifestyles of Chinese oldestold and how health lifestyles have played an important role in shaping Chinese oldest-old's health outcomes. Through analyzing sample aged 85 to 105 from data of the CLHLS 2014 wave, the research found four latent classes representing four predominant health lifestyles among studied Chinese oldest-old. The four classes included: (1) class 1, with poor sleep issue (32.4\% of total sample), class 2 , classified as a sedentary group (33.6\% of all sample), class 3 , defined as "consistent engagement in healthy behavior" group (21.9\% of total sample), and class 4 , the group with smoking and drinking problems ( $12.1 \%$ of all sample). The percentage distributions of sample across the four latent classes suggested that individuals with poor sleep and sedentary lifestyles accounted for two thirds of the studied sample, which represented the most popular health lifestyles of Chinese oldest-old. Only $21.9 \%$ of the respondents demonstrated consistently healthy lifestyles.

The research also showed that healthier lifestyles resulted in better health outcomes. The findings highlighted that consistent engagement in healthy behaviors linked to better $\mathrm{SRH}$, higher cognitive function scores and a lower likelihood of being functional dependent and suffering chronic conditions. These results suggested that practicing healthier lifestyles can be an effective way to improve Chinese oldest-old's health status and postpone long-term disabilities. In this sense, the research results echoed arguments of researchers that multiple health behavior change interventions outperformed single-behavior interventions in health promotion $[60,61]$. Findings of this study certainly provided strong proof that applying an integrative approach rather than individual health behavior perspective can be a better way to achieve a more effective health promotion. Healthy lifestyles were proved to be an important tool to prevent chronic diseases and long term disabilities among the oldest-old. Findings based on analyzing the China data also provided valuable implications to address disease prevention and health promotion related issues among older adults in other countries. Caregivers, clinicians and professionals can educate the elderly and their family to form healthier lifestyles in order to improve the oldest-old's health status and longevity.

The significant impacts of the covariates on Chinese oldest-old's health outcomes also had important implications. Gender only showed significant effects on cognitive function scores and ADL disabilities, with males doing better on these two dimensions than females. Age generally showed significantly negative effects on health of the oldest-old, except for chronic conditions. The exception may be explained by the survival selection theory that the oldest-old with severe chronic illnesses had already died or been censored. Thus, older ages showed a negative effect on chronic

Page 9/23 
conditions among survived individuals. Higher education and income was associated with better cognitive function. Higher income and holding professional jobs also linked to greater risks of reporting chronic disease(s). This finding seemed to be incongruent with results documented in prior literature that higher SES led to better health outcomes. Such inconsistency may be explained by underreporting of chronic illnesses among disadvantaged groups in China due to limited access to medical services and diagnoses. It can also be caused by the fact that people with higher SES in China have a more sedentary lifestyle and consume more high-fat and energy-condensed food, which resulted in a prevalence of chronic conditions. Another issue that worth mentioning is the urban and rural divide that has been documented repeatedly in prior literature $[62,63]$. Nevertheless, findings of this research did not show significant health differentials among the oldest-old in these two spheres. The health disparities caused by residence only showed on the measure of ADL disabilities. That is, as compared to rural residents, urban oldest-old had a significantly higher likelihood of having ADL disabilities. The significant health differentials showed in ADL disabilities may be explained by various lifestyles among urban and urban individuals. Farming and laboring work could have beneficial effects on postponing the onset of ADL disabilities among rural seniors. Except that the variable going to bed hungry showed a significantly negative effect on the oldest-old's cognitive function, the other parental SES measures had nonsignificant influence on individual health. The results suggested a convergence trend of health differentials caused by one's demographic and SES characteristics in very old ages. But even after controlling for these characteristics, the significant impact of health lifestyle measures on Chinese oldest-old's health outcomes still existed. The findings once again underscored the importance of health lifestyles in explaining the health disparities.

The study had several limitations. First and foremost, relying on examining the CLHLS dataset, the research was not able to exhaust all possible health lifestyle measures due to limited survey questions relating to health lifestyles. Some important health lifestyle indicators, such as vaccination injections, wearing seat belt, dental visits and et al. have not been included in this research. Secondly, measures of one's health status were also relatively crude. Future research may consider applying additional health outcome measures to examine the association between Chinese oldest-old's health lifestyles and their health outcomes. Lastly, multiple regression models showed significant effects of health lifestyles on Chinese oldest-old's health status. But the issue of causality has not been fully sorted out. It could be case that healthier individuals are more likely to have healthier lifestyles, which in turn benefits one's health. Future research should further address the causality issue and unravel the interconnectedness of health lifestyles and elderly health status.

\section{Conclusion}

Through analyzing data of the CLHLS 2014 wave, this research pointed out four latent classes representing four predominant health lifestyles among Chinese oldest-old. The four classes can be described as: class with poor sleep issue (class $1,32.4 \%$ of total sample), a sedentary group (class $2,33.6 \%$ of all sample), consistent engagement in healthy behavior group (class $3,21.9 \%$ of total sample), and the group with smoking and drinking problems (class 4 , $12.1 \%$ of all sample). Overall, the majority of Chinese oldest-old tended to have sedentary lifestyles with poor sleep issues. Only $21.9 \%$ of the respondents showed consistently healthy lifestyles. The research also proved that healthier lifestyles resulted in better health status. These results suggested that practicing healthier lifestyles can be an effective way to improve the oldest-old's health status and postpone long-term disabilities. The research also contained important implications that educating the elderly and their family to form healthier lifestyles can be an effective way to advance the oldest-old's health status and to promote longevity.

\section{Declarations}

\section{Ethics approval and consent to participate}

Page $10 / 23$ 
Not applicable.

\section{Consent for publication}

Not applicable.

\section{Availability of data and materials}

This article is based on a publicly available dataset derived from the Chinese Longitudinal Healthy Longevity Survey (CLHLS). The dataset can be obtained after sending a data user agreement to the data team.

\section{Competing interests}

The authors declare that they have no conflicts of interest.

\section{Funding}

The study was supported by Program for Young Innovative Research Team in China University of Political Science and Law (Grant No.CXTD19-04). It was also funded by the Fundamental Research Funds for Central Universities. The funders had no role in the design of the study, in collection, analysis and interpretation of data, and in writing the manuscript.

\section{Authors' contributions}

LZ was a major contributor in designing the research, writing the manuscript, conducting literature review and analyzing data. BXY and ZHD analyzed and interpreted the data; they also revised the earlier version of the paper. All authors read and approved the final manuscript.

\section{Acknowledgments}

Data used for this research were provided by the Chinese Longitudinal Healthy Longevity Survey (CLHLS), managed by the Center for Healthy Aging and Family Studies, Peking University. The authors are grateful for the above institute and organizing members.

\section{References}

1. Burdette A, Needham B, Taylor M, Hill T: Health lifestyles in adolescence and self-rated health into adulthood. . Journal of Health and Social Behavior 2017, 58:520-536.

2. Conry MC: The clustering of health behaviours in Ireland and their relationship with mental health, self-rated health and quality of life. BMC Public Health 2011, 11:692.

3. Lawrence E, Mollborn S, Hummer R: Health lifestyles across the transition to adulthood: implications for health. . Social Science \& Medicine 2017, 193:23-32.

4. Vermeulen-Smit E, Ten Have M, Van Laar M, De Graaf R: Clustering of health risk behaviours and the relationship with mental disorders. Journal of Affective Disorders 2015, 171:111-119.

5. Biddle SJH, Bennie JA, Bauman AE: Too much sitting and all-cause mortality: is there a causal link? BMC Public Health 2016, 16:635.

6. Erkki K, Tiina L, Markku P, Risto S, Timo P: Self-reported sleep duration, all-cause mortality, cardiovascular mortality and morbidity in Finland. Sleep Medicine 2011, 12:215-221. 
7. Bengtsson T, Mineau GP: Early-Life Effects on Socio-economic Performance and Mortality in Later Life: A Full LifeCourse Approach Using Contemporary and Historical Sources. Social Science \& Medicine 2009, 68(9):1561-1564.

8. Bots S, Tijhuis M, Giampaoli S, Kromhout D, Nissinen A: Lifestyle- and diet-related factors in late-life depression-A 5-year follow-up of elderly European men: The FINE study. International Journal of Geriatric Psychiatry 2008, 23:478-484.

9. Rogers R, Hummer RA, Krueger PM, Pampel FC: Mortality Attributable to Cigarette Smoking in the United States. Population and Development Review 2005, 31(1):259-292.

10. Cockerham WC: Health lifestyle theory and the convergence of agency and structure. Journal of Health and Social Behavior 2005, 46(1):51-67.

11. Frohlich KL, Corin E, Potvin L: A theoretical proposal for the relationship between context and disease. Sociology of Health IIIness 2001, 23(6):776-797.

12. Spring B, Moller AC, Coons MJ: Multiple health behaviors: overview and implications. Journal of Public Health 2012, 34(S1):i3-i10.

13. Chen F, Yang Y, Liu G: Social Change and Socioeconomic Disparities in Health over the Life Course in China: A Cohort Analysis. American Sociological Review 2010, 75(1):126-150

14. Ding ZH, Du SR, Wang MX: Research on the Falls and Its Risk Factors among the Urban Aged in China. Population and Development (in Chinese) 2018, 24(4):120-129.

15. Wen M, Gu D: The Effects of Childhood, Adult, and Community Socioeconomic Conditions on Health and Mortality among Older Adults in China. Demography 2011, 48(1):153-181.

16. Zhao Y, Dupre ME, Qiu L, Gu D: Changes in perceived uselessness and risks for mortality: evidence from a National sample of older adults in China. BMC Public Health 2017, 17:561.

17. Bourdieu P (ed.): Distinction: a social critique of the judgment of taste. Cambridge, MA: Harvard University Press; 1984.

18. Dodd LJ, Al-Nakeeb Y, Nevili A, Forshaw MJ: Lifestyle Risk Factors of Students: A Cluster Analytical Approach. Preventive Medicine 2010, 51(1):73-77.

19. Chan CW, Leung SF: Lifestyle Health Behaviors of Hong Kong Chinese: Results of a Cluster Analysis. Asia-Pacific Journal of Public Health 2015, 27:293-302.

20. Christensen VT, Carpiano RM: Social class differences in BMI among Danish women: Applying Cockerham's health lifestyles approach and Bourdieu's theory of lifestyle. . Social Science \& Medicine 2014, 112:12-21.

21. Glorioso V, Pisati M: Socioeconomic inequality in health-related behaviors: A lifestyle approach. Quality and Quantity 2014, 48(5):2859-2879.

22. Pampel FC, Krueger PM, Denney JT: Socioeconomic Disparities in Health Behaviors. Annual Review of Sociology 2010, 36:349-370.

23. French A: Healthy behavior trajectories between adolescence and young adulthood. Advances in Life Course Research 2012, 17(2):59-68.

24. McGovern CM, Militello LK, Arcoleo KJ, Melnyk BM: Factors Associated with Healthy Lifestyle Behaviors among Adolescents. Journal of Pediatric Health Care 2018, published online.

25. Guallar-Castillón P, Bayán-Bravo A, León-Munoz LM: The association of major patterns of physical activity, sedentary behavior and sleep with health-related quality of life: A cohort study. Preventive Medicine 2014, 67:248254.

26. Oftedal S, Kolt GS, Holliday EG, Stamatakis E, Vandelanotte C, Brown WJ, Duncan MJ: Associations of healthbehavior patterns, mental health and self-rated health. Preventive Medicine 2019, 118:295-303. 
27. Claas SA, Arnett DK: The Role of Healthy Lifestyle in the Primordial Prevention of Cardiovascular Disease. Current Cardiology Reports 2016, 18(6):56.

28. Khan N, Afaq F, Mukhtar H: Lifestyle as risk factor for cancer: Evidence from human studies. Cancer Letters 2010, 293(2):133-143.

29. Martín-María N, Caballero FF, Moreno-Agostino D, Olaya B, Haro JM, Ayuso-Mateos JL, Miret M: Relationship between subjective well-being and healthy lifestyle behaviours in older adults: a longitudinal study. Aging \& Mental Health 2018, Published online:1-8.

30. Lee Y, Kim J, Back JH, Kim S, Ryu M: Changes in combined lifestyle risks and disability transition in older adults: Korean Longitudinal Study of Aging, 2006-2008. Preventive Medicine 2013, 56:124-129.

31. Visser M, Wijnhoven HAH, Comijs HCC, Thomése FGCF, Twisk JWR, Deeg DJHD: A Healthy Lifestyle in Old Age and Prospective Change in Four Domains of Functioning. Journal of Aging and Health 2019, 31(7):1297-1314.

32. Rizzuto D, Orsini N, Qiu C, Wang HX, Fratiglioni L: Lifestyle, social factors, and survival after age 75: population based study. Journal of Aging and Health 2019, 31(7):1297-1314.

33. Zeng Y, Vaupel J, Xiao Z, Zhang C, Liu Y: Sociodemographic and health profiles of the oldest old in China. Population and Development Review 2002, 28:251-273.

34. Daw J, Margolis R, Wright L: Emerging adulthood, emerging health lifestyles: sociodemographic determinants of trajectories of smoking, binge drinking, obesity, and sedentary behavior. Journal of Health and Social Behavior 2017, 58:181-197.

35. Saint Onge JM, Krueger PM: Health lifestyle behaviors among U.S. adults. SSM Population Health 2017, 3:89-98.

36. Martín-María N, Caballero FF, Moreno-Agostino D, Olaya B, Haro JM, Ayuso-Mateos JL, Miret M: Relationship between subjective well-being and healthy lifestyle behaviours in older adults: a longitudinal study. Aging \& Mental Health 2020, 24:611-619.

37. Visser M, Wijnhoven HAH, Comijs HCC, Thomése FGCF, Twisk JWR, Deeg DJHD: A Healthy Lifestyle in Old Age and Prospective Change in Four Domains of Functioning. Journal of Aging and Health 2019, 31:1297-1314.

38. Wang F: Status constraint and lifestyle transition: a latent class analysis of health-related lifestyles among different social strata in China. The Journal of Chinese Sociology 2019, 6.

39. Li Y: Healthy lifestyle and life expectancy free of cancer, cardiovascular disease, and type 2 diabetes: prospective cohort study. BMJ 2020, 368.

40. Burdette A, Needham B, Taylor M, Hill T: Health lifestyles in adolescence and self-rated health into adulthood. Journal of Health and Social Behavior 2017, 58:520-536.

41. Xiao YX, Romanelli M, Lindsey MA: A latent class analysis of health lifestyles and suicidal behaviors among U.S. adolescents. Journal of Affective Disorder 2019, 255:116-126.

42. Ruan R, Feng L, Li J, Ng TP, Zeng Y: Tea Consumption and Mortality among oldest-old Chinese. Journal of American Geriatric Society 2013, 61:1-13.

43. Ferraro K, Schafer M, Wilkinson L: Childhood disadvantage and health problems in middle and later life: Early imprints on physical health? . American Sociological Review 2016, 81:107-133.

44. Wagner DC, Short JL: Longitudinal predictors of self-rated health and mortality in older adults. Preventing Chronic Disease 2014, 11:E93.

45. Lee Y, Kim J, Back JH: The influence of multiple lifestyle behaviors on cognitive function in older persons living in the community. Preventive Medicine 2008, 48:86-90.

46. Lv X, Li W, Ma Y, Chen H, Zeng Y, Yu X, Hofman A, Wang H: Cognitive decline and mortality among communitydwelling Chinese older people. BMC Medicine 2019, 17:63. 
47. Bielak AA, Anstey KJ, Christensen $\mathrm{H}$, Windsor TD: Activity engagement is related to level, but not change in cognitive ability across adulthood. Psychology and Aging 2012, 27(1):219-228.

48. Han SH, Tavares JL, Evans M, Saczynski J, Burr JA: Social activities, incident cardiovascular disease, and mortality. Journal of Aging and Health 2017, 29:268-288.

49. Gu D, Zeng Y: Sociodemographic Effects on the Onset and Recovery of ADL Disability among Chinese Oldest-Old. Demographic Research 2004, 11:1-42.

50. Smith K, Victor C: Typologies of loneliness, living alone and social isolation, and their associations with physical and mental health. Aging \& Society 2019, 39:1709-1730.

51. Folstein MF, Folstein SE, McHugh PR: "Mini-mentalstate": A practical method for grading the cognitive state of patients for the clinician. Journal of Psychiatric Research 1975, 12:189-198. .

52. Herzog AR, Wallace RB: Measures of cognitive functioning in the AHEAD study. Journal of Gerontology: Social Sciences 1997, 52B(Special Issue):S37-S48.

53. Luo Y, Waite LJ: The Impact of Childhood and Adult SES on Physical, Mental, and Cognitive Well-Being in Later Life. The Journals of Gerontology Series B: Psychological Sciences \& Social Sciences 2005, 60(2):S93-S101.

54. Zeng Y, Gu D, Land KC: The association of childhood socioeconomic conditions with healthy longevity at the oldest-old ages in China. Demography 2007, 44(3):497-518.

55. Brashera MS, George LK, Shi X, Yine Z, Zeng Y: Incorporating biomarkers into the study of socio-economic status and health among older adults in China. SSM - Population Health 2017, 3:577-585.

56. Shen K, Yan P, Zeng Y: Coresidence with elderly parents and female labor supply in China. Demographic Research 2016, 35:645-670.

57. Lv X, Li W, Ma Y, Chen H, Zeng Y, Yu X, Hofman A, Wang H: Cognitive decline and mortality among communitydwelling Chinese older people. BMC Medicine 2019, 17(63).

58. Vermunt JK: Latent class modeling with covariates: two improved three-Step approaches. Political Anal 2010, 18:450-469.

59. Asparouhov T, Muthén B: Auxiliary Variables in Mixture Modeling: Three-Step Approaches Using Mplus. Structural Equation Modeling: A Multidisciplinary Journal 2014, 21(3):329-341.

60. Prochaska JJ, Spring B, Nigg CR: Multiple health behavior change research: an introduction and overview. Preventive Medicine 2008, 46(1):181-188.

61. Wilson K, Senay I, Durantini M, Sanchez F, Hennessy M, Spring B, Albarracín D: When it comes to lifestyle recommendations, more is sometimes less: a metaanalysis of theoretical assumptions underlying the effectiveness of interventions promoting multiple behavior domain change. Psychological Bulletin 2015, 141:474509.

62. Zimmer Z, Kwong J: Socioeconomic Status and Health among Older Adults in Rural and Urban China. Journal of Aging and Health 2004, 16(1):44-70.

63. Qun SU, Binxia P, Jie C: An analysis on long-term care and influencing factors of the disabled elders: Based on rural-urban difference. Population \& Economics 2015, 4:69-76.

\section{Tables}


Table 1. Summary Statistics for All Variables: Chinese Older Adults Aged 85-105 $(\mathrm{N}=3,416)$

Variables

Mean (or \%) SD

$\mathrm{N}$

Health lifestyle variables

1) If $R$ eats fresh fruit almost everyday

Yes

13.5

No

86.5

2) If $R$ eats fresh vegetables almost everyday

Yes

49.1

3,347

No

50.9

3) If R drinks tea almost everyday

Yes

17.2

No

82.8

4) If R smoked before and is still a smoker

Yes

24.9

No

75.1

5) If $R$ drank before and is still a drinker

Yes

21.3

No

78.7

6) R's quality of sleep

Good

60.4

Poor

39.1

7) If R normally sleeps at least 8 hours

Yes

55.3

No

44.7

8) If $R$ exercised during the past and still exercises at present

Yes

26.8

No

73.2

9) If $R$ participates active leisure activities

Yes

48.4

No

51.6

10) If R participates sedentary leisure activities

Yes

41.7

No

58.3

Page 15/23 
11) If $R$ has physical exam once a year

Yes

No

Health status variables

1) R's self-rated health (mean)

2) If $R$ reports at least one type of chronic illnesses

Yes

No

3) If R has ADL disability

Yes

No

4) R's cognitive function score (mean)

5) If R overweight

Yes

No

\section{Control variables}

\section{$\underline{R}$ 's characteristics}

Age (mean)

Gender $($ male $=1)$

Male

Female

Rural/urban residence (urban $=1$ )

Urban

Rural

R's reported years of schooling (mean)

R's household per capita income

R's had professional or administrative job before age 60

Yes

No

R's Parental characteristics

Whether R often went to bed hungry in childhood
51.6

48.4

3.3

0.9

2,977

3,416

57.1

42.9

3,416

34.8

65.2

22.5

8.0

2,440

93.1

5.7

3,416

3,416

40.7

59.3

42.7

57.3

$\begin{array}{lll}1.5 & 2.8 & 3,364 \\ 15,832.8 & 17,233.8 & 2,388 \\ & & 3,115\end{array}$

5.7

94.3 


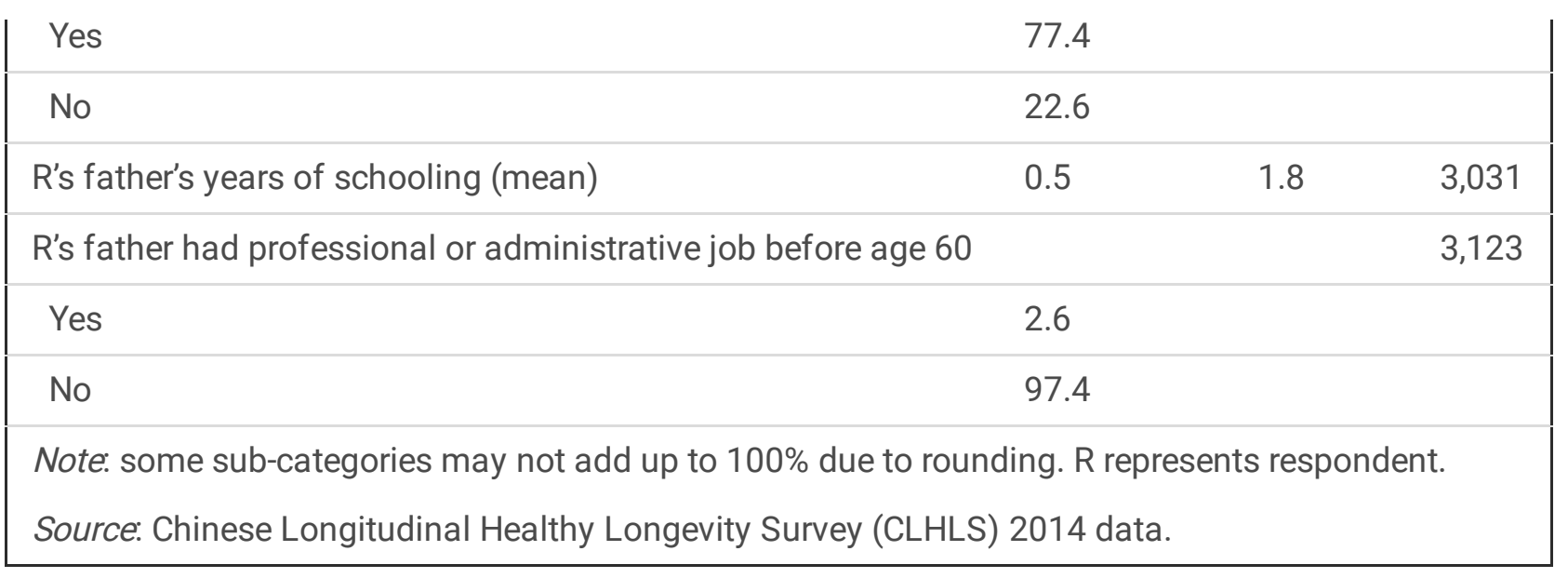

\begin{tabular}{|lllll|}
\hline \multicolumn{4}{|l|}{ Table 2. Summary of Latent Class Model Identification and Statistics (N=3ロ267) } \\
\hline No .of classes & AIC & BIC & Entropy & Likelihood ratio chi-squared \\
\hline 1 & 38847.4 & 38908.3 & - & 3549.2 \\
\hline 2 & 37576.3 & 37704.2 & .663 & 2256.2 \\
\hline 3 & 37064.4 & 37259.4 & .733 & 1722.3 \\
\hline 4 & $\mathbf{3 6 7 8 8 . 7}$ & $\mathbf{3 7 0 5 0 . 6}$ & .732 & $\mathbf{1 4 2 4 . 5}$ \\
\hline $\begin{array}{l}\text { Note: AlC: Akaike's information criterion, BIC: Bayesian information criterion. Bolded row represents the identified } \\
\text { model. }\end{array}$
\end{tabular}


Table 3. Item Response Probabilities for Health Lifestyle Indicators Used in Latent Class Analysis: Chinese Older Adults Aged 85-105, 2014

Variables

Class 1
(less healthy diet, not
smoking, not drinking,
poor sleep, low physical
exercise \& leisure
activities;

$32.4 \%)$

\section{Class 2}

(less healthy diet, not smoking, not drinking, good sleep, lowest physical exercise \& leisure activities;

$33.6 \%)$

\section{Class $3 \quad$ Class 4}

(consistent (moderate diet, smoking engagement and drinking, moderate in healthy behaviors;

$21.9 \%)$ sleep, moderate exercise and leisure activity engagement;

$12.1 \%)$

Health

lifestyle

indicators

1) Eating fresh fruit

almost

everyday

$\begin{array}{lrrrr}\text { Yes } & .038 & .122 & .314 & .111 \\ \text { No } & .962 & .878 & .686 & .889\end{array}$

2) Eating

fresh

vegetables

almost

everyday

$\begin{array}{lrrrr}\text { Yes } & .331 & .467 & .820 & .554 \\ \text { No } & .669 & .533 & .180 & .446\end{array}$

3) Drinking

tea almost

everyday

$\begin{array}{lrrrr}\text { Yes } & .095 & .093 & .313 & .337 \\ \text { No } & .905 & .907 & .687 & .663\end{array}$

4) Smoking

$\begin{array}{lllll}\text { Yes } & .099 & .119 & .299 & .922 \\ \text { No } & 901 & .881 & .701 & .078\end{array}$

5) Drinking

$\begin{array}{lrrrr}\text { Yes } & .089 & .109 & .190 & .865 \\ \text { No } & . .911 & .891 & .810 & .135\end{array}$

6) Good quality of sleep

$\begin{array}{lrrrr}\text { Good } & .191 & .932 & .679 & .661 \\ \text { Poor } & .809 & .068 & .321 & .339\end{array}$

7) Normally sleeps at 


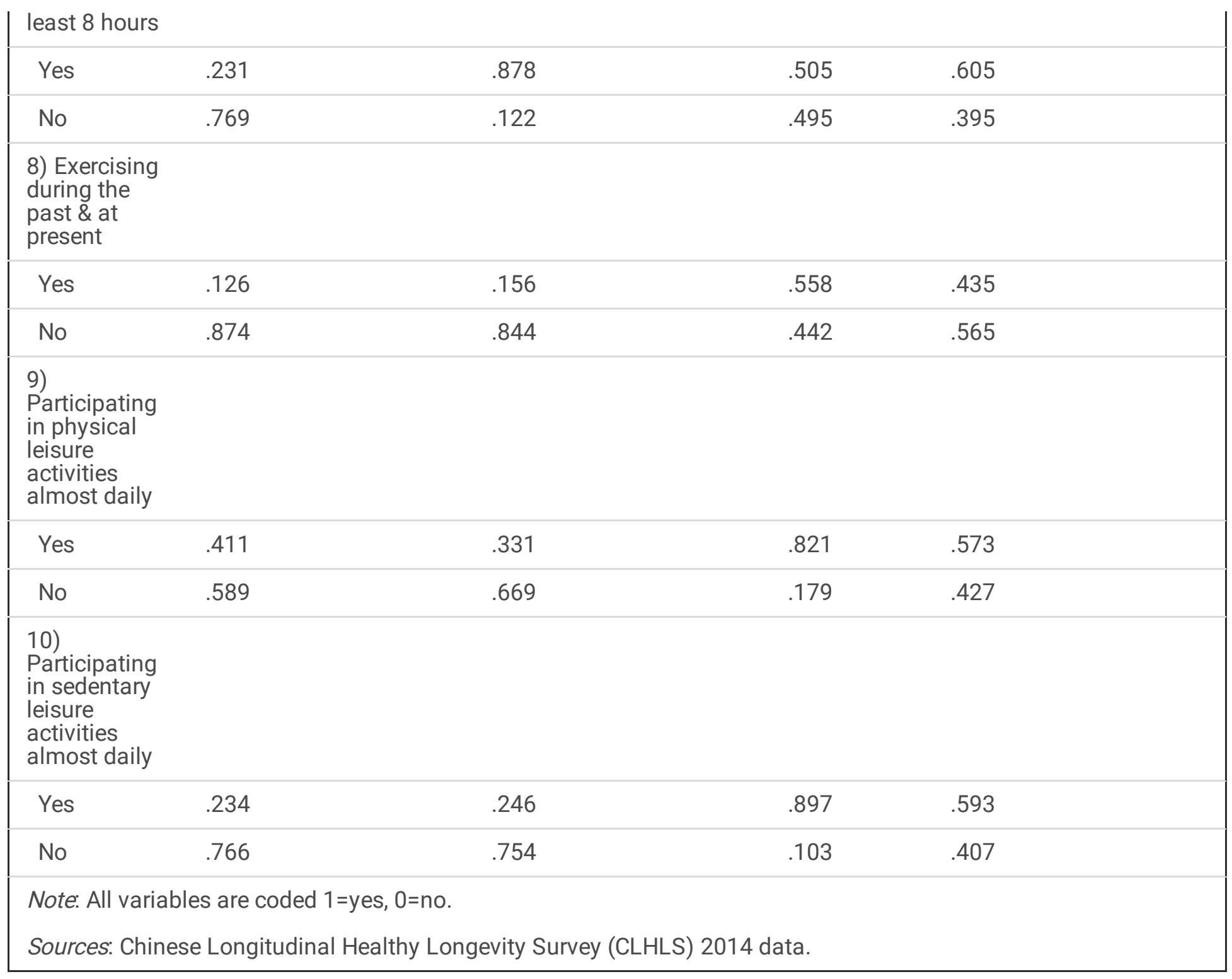


Table 4. OLS Regression of Self-Rated Health and Cognitive Function Status on Health Lifestyle Latent Classes and Other Control Variables: Chinese Older Adults Aged 55-105, 2014

Variables

Self-Rated Health

Cognitive Function

\begin{tabular}{llllllll} 
Model 1 & \multicolumn{3}{c}{ Model 2 } & \multicolumn{3}{c}{ Model 3 } & \multicolumn{3}{c}{ Model 4} \\
b & S.E. & b & S.E. & b & S.E. & b & S.E.
\end{tabular}

Health Lifestyle

Latent Class

(Ref.= Class 3:

Consistent

engagement in

healthy behaviors)

Class 1 (less healthy

diet, not smoking, not

$-0.59 * * *$

0.06

$-0.56^{\star \star *} \quad 0.06$

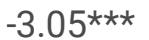

0.54

$-2.98 * \star \star$

0.56

drinking, poor sleep,

low physical exercise

\& leisure activities)

Class 2 (less healthy

diet, not smoking, not

$-0.21^{\star * *} \quad 0.06$

$-0.21 * \star * \quad 0.06$

$-3.40 * \star \star$

0.53

$-3.45^{\star \star *}$

0.55

drinking, good sleep,

lowest physical

exercise \& leisure

activities)

Class 4 (moderate

diet, smoking and

drinking, moderate

sleep, moderate

exercise and leisure

activity engagement)

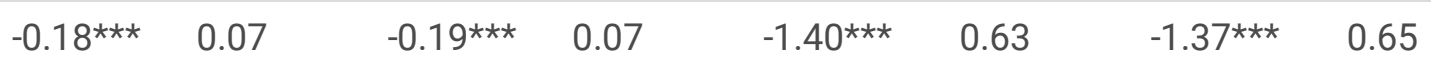

\section{Control Variables}

\begin{tabular}{|c|c|c|c|c|c|c|c|c|}
\hline Age & $0.00 * \star \star$ & 0.00 & $0.00 \star \star \star *$ & 0.01 & $-0.41 * \star \star$ & 0.03 & $-0.41 * \star \star$ & 0.04 \\
\hline Sex (Ref. = female) & -0.07 & 0.05 & 0.06 & 0.04 & $1.58^{\star \star \star}$ & 0.44 & $1.64^{\star \star \star}$ & 0.46 \\
\hline $\begin{array}{l}\text { Residence (Ref. = } \\
\text { rural) }\end{array}$ & 0.01 & 0.04 & -0.01 & 0.01 & $0.67 *$ & 0.38 & 0.33 & 0.39 \\
\hline $\begin{array}{l}\text { R's years of } \\
\text { schooling }\end{array}$ & 0.01 & 0.00 & 0.01 & 0.02 & $0.26 * \star \star$ & 0.08 & $0.19 *$ & 0.39 \\
\hline $\begin{array}{l}\text { R's natural logged } \\
\text { per capita family } \\
\text { income }\end{array}$ & $0.04 *$ & 0.02 & $0.05^{\star}$ & 0.02 & $0.49 * * *$ & 0.18 & $0.51^{\star \star}$ & 0.19 \\
\hline $\begin{array}{l}\text { R's occupation } \\
\text { before age } 60 \text { (Ref. = } \\
\text { nonprofessional or } \\
\text { non-administrative) }\end{array}$ & 0.11 & 0.09 & 0.13 & 0.10 & 0.33 & 0.88 & 0.13 & 0.93 \\
\hline $\begin{array}{l}\text { If } R \text { often when to } \\
\text { bed hungry in } \\
\text { childhood }\end{array}$ & & & -0.06 & 0.05 & & & $-0.98^{*}$ & 0.46 \\
\hline
\end{tabular}




\begin{tabular}{|c|c|c|c|c|c|c|c|c|}
\hline $\begin{array}{l}\text { R's father's years of } \\
\text { schooling }\end{array}$ & & & -0.01 & 0.01 & & & 0.14 & 0.11 \\
\hline $\begin{array}{l}\text { R's father's } \\
\text { occupation before } \\
\text { age } 60\end{array}$ & & & 0.02 & 0.14 & & & -.055 & 1.30 \\
\hline $\begin{array}{l}\text { (Ref. }= \\
\text { nonprofessional or } \\
\text { non-administrative) }\end{array}$ & & & & & & & & \\
\hline Constant & $2.07 * \star \star *$ & 0.39 & $1.90 * \star \star$ & 0.41 & $56.62^{\star \star \star}$ & 3.71 & 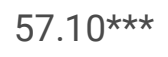 & 3.87 \\
\hline $\mathrm{N}$ & 1,896 & & 1,727 & & 1,558 & & 1,425 & \\
\hline
\end{tabular}

Note: $*<. .05, * *<.01, * * *<.001$. R represents the respondent. b: regression coefficient; S.E.: standard error. Sources: Chinese Longitudinal Healthy Longevity Survey (CLHLS) 2014 data. 
Table 5. Logistic Regression of ADL Disability and Chronic Disease Status on Health Lifestyle Latent Classes and Other Control Variables: Chinese Older Adults Aged 85-105, 2014

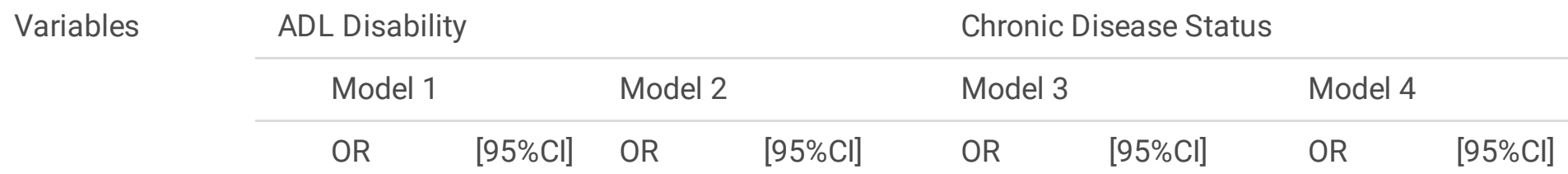

Health Lifestyle

Latent Class

(Ref.= Class 3:

Consistent

engagement in

healthy

behaviors)

Class 1 (less

healthy diet, not

smoking, not

drinking, poor

sleep, low

physical

exercise \&

leisure

activities)

Class 2 (less

healthy diet, not

smoking, not

drinking, good

sleep, lowest

physical

exercise \&

leisure

activities)

Class 4

(moderate diet,

smoking and

drinking,

moderate sleep,

moderate

exercise and

leisure activity

engagement)

$\begin{array}{llllllll}2.83^{\star * *} & {[2.10-} & 2.98 * \star * & {[2.15-} & 1.27 * & {[0.97-} & 1.27 * & {[0.96-} \\ & 3.79] & & 4.01] & & 1.65] & & 1.68]\end{array}$

$\begin{array}{llllllll}2.78 * * * & {[2.08-} & 2.91^{* * *} & {[2.15-} & 1.06 & {[0.82-} & 1.09 & {[0.83-} \\ & 3.71] & & 3.95] & & 1.37] & & 1.43]\end{array}$

$1.35^{\star}$

3.87]
[0.99-

$-1.86]$
$1.48^{* *}$

[1.06-

2.06]

\section{Control}

Variables

Age

$1.09 * \star * \quad[1.07-$

$1.11]$

$1.10 * * * \quad[1.08-$

1.12]

0.95

$[0.93-$

0.97]

$0.94^{\star \star \star}$

[0.93-

[0.62- $0.79 * \quad[063-$

Sex (Ref. =

$0.77 *$

$0.96]$

1.00]

0.93

[0.75-

1.15]

0.92

0.96 ]

female)

1.79*** [1.48-

$1.74^{\star \star \star}$

[1.42-

2.17]

2.13]

1.16

[0.96-

1.39]

1.17

$1.15]$

= rural)

R's years of

1.01

[0.97-

1.01

[0.96-

1.05]

1.02

[0.98-

1.06]

1.01

R's natural

logged per

1.07

[0.98-

1.06

[0.96-

1.17]

$\begin{array}{ll}1.18 * * * & {[1.08-} \\ & 1.28]\end{array}$

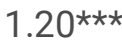

[1.09

Page 22/23 
capita family

income

R's occupation

before age 60

1.42

[0.91-

$1.51^{*}$

[0.93-

$2.01^{\star * *} \quad[1.23-$

$1.97 * \star \star$

[1.17-

(Ref. =

nonprofessional

or non-

administrative)

If $R$ often when

$0.97 \quad[0.76-$

0.94

[0.75-

to bed hungry in

1.22]

$1.18]$

childhood

\begin{tabular}{|c|c|c|c|c|c|c|c|c|}
\hline $\begin{array}{l}\text { R's father's } \\
\text { years of } \\
\text { schooling }\end{array}$ & & & 0.98 & $\begin{array}{l}{[0.49-} \\
1.96]\end{array}$ & & & 0.82 & $\begin{array}{l}{[0.41-} \\
1.64]\end{array}$ \\
\hline $\begin{array}{l}\text { R's father's } \\
\text { occupation } \\
\text { before age } 60\end{array}$ & & & 0.99 & $\begin{array}{l}{[0.94-} \\
1.06]\end{array}$ & & & 1.02 & $\begin{array}{l}{[0.97-} \\
1.09]\end{array}$ \\
\hline $\begin{array}{l}\text { (Ref. = } \\
\text { nonprofessional } \\
\text { or non- } \\
\text { administrative) }\end{array}$ & & & & & & & & \\
\hline Constant & $0.01^{\star \star \star *}$ & $\begin{array}{l}{[0.00-} \\
0.00]\end{array}$ & $0.01^{* * \star}$ & $\begin{array}{l}{[0.00-} \\
0.00]\end{array}$ & $32.67 * \star$ & $\begin{array}{l}{[5.86-} \\
182.23]\end{array}$ & $48.87^{\star \star}$ & $\begin{array}{l}{[1.89-} \\
302.74]\end{array}$ \\
\hline $\mathrm{N}$ & 2,157 & & 1,955 & & 2,157 & & & \\
\hline
\end{tabular}

Note: ${ }^{*}<. .05, * \star<.01, * \star \star<.001 . \mathrm{R}$ represents the respondent. OR: odds ratio; Cl: confidence interval.

Sources: Chinese Longitudinal Healthy Longevity Survey (CLHLS) 2014 data. 